\title{
The Severity of Sleep Disordered Breathing Induces Different Decrease in the Oxygen Saturation During Rapid Eye Movement and Non-Rapid Eye Movement Sleep
}

\author{
Eunkyung Choi, Doo-Heum Park ${ }^{\bowtie}$, Jae-hak Yu, Seung-Ho Ryu, and Ji-Hyeon Ha \\ Department of Psychiatry, School of Medicine Konkuk University, Seoul, Republic of Korea
}

Objective To investigate how differences in oxygen saturation between non-REM (NREM) and REM sleep in patients according to the severity of sleep apnea.

Methods We studied 396 male patients diagnosed with simple snoring or obstructive sleep apnea syndrome (OSAS) on nocturnal polysomnography. Patients were divided into groups by the OSAS severity. We compared the average oxygen saturation between REM and NREM sleep in each group.

Results In the simple snoring group, average oxygen saturation was significantly greater during REM than during NREM sleep. In the severe OSA group alone, average oxygen saturation was greater in NREM than in REM sleep. The difference of NREM-REM average oxygen saturation correlated significantly with AHI in the severe OSA group.

Conclusion More severe hypoxemia was seen in REM than NREM sleep in the severe OSAS group. The differential oxygen decrease between REM and NREM sleep is likely due to the differentially occurring sleep breathing events in each sleep stage according to the SDB severity. The more AHI increases in the severe OSAS patients, the more prominent the hypoxemia of REM sleep compared with NREM sleep is likely to appear. This suggests that the pressure of continuous positive airway pressure should be increased to control the hypoxemia of REM sleep in extremely severe OSAS.

Psychiatry Investig 2016;13(6):652-658

Key Words Sleep disordered breathing, Obstructive sleep apnea, Oxygen saturation, Non-REM sleep, REM sleep.

\section{INTRODUCTION}

There is a difference between the breathing pattern while awake and asleep. While awake, intentional breathing control takes priority over automatic breathing; in contrast, this changes after falling asleep. When sleeping, breathing changes in accordance with the stage of sleep. ${ }^{1}$ The fact that patients with obstructive sleep apnea have apnea and patients with chronic pulmonary disease have hypoxia is related to these changes. That is, while awake, the system that controls breathing operates effectively. In contrast, during sleep, the breathing control system becomes relatively unstable, and interacts with collaps-

Received: March 23, 2016 Revised: May 5, 2016

Accepted: May 17, 2016 Available online: November 21, 2016

$\square$ Correspondence: Doo-Heum Park, MD, PhD

Department of Psychiatry, School of Medicine Konkuk University, 120-1 Neungdong-ro, Gwangiin-gu, Seoul 05030, Republic of Korea

Tel: +82-2-2030-7568, Fax: +82-2-2030-7749, E-mail: dhpark@kuh.ac.kr

(c) This is an Open Access article distributed under the terms of the Creative Commons Attribution Non-Commercial License (http://creativecommons.org/licenses/by$\mathrm{nc} / 3.0$ ) which permits unrestricted non-commercial use, distribution, and reproduction in any medium, provided the original work is properly cited. ing forces that affect characteristic anatomic structures, such as the pharyngeal airway, weakened reactions of the muscles of the upper airway, and arousal threshold. This leads to, and affects the severity of, sleep apnea. ${ }^{2}$

Sleeping is categorized into two main phases: rapid eye movement (REM) and non-rapid eye movement (NREM) sleep. During REM sleep, breathing is irregular, with shallow amplitude, and low frequency. Hypoxemia, often due to hypoventilation, is often observed in comparison with NREM sleep. That is, during REM sleep, the oxygen saturation is generally lower than that during NREM sleep. In comparison with being awake, during REM sleep, arterial oxygen saturation is lowered; when hypoventilation occurs, arterial oxygen saturation decreases further. ${ }^{3,4}$

The mechanism of this phenomenon has not yet been revealed, but it may be due to the fact that during REM sleep the tension of muscles that expand the thoracic cavity is relatively decreased, but the resistance of the upper airway is increased, weakening ventilation. ${ }^{5}$

During REM sleep, there is a decrease in the muscular 
strength of the intercostal and other breathing-related muscles, except for the diaphragm. During NREM sleep, sound pressure reflections gradually decreases, and further decrease during REM sleep. ${ }^{1,6}$ Hypoxia, due to apnea during REM sleep, may be closely related to the aftereffects and dysfunctions of sleep apnea such as daytime sedation and cognitive impairment. In this regard, it is of particular clinical importance.

It is known that when the ventilatory response to hypoxemia decreases during sleep, it differs by sex. ${ }^{8}$ In the case of both men and women, the ventilatory response to hypoxemia decreases more during REM than NREM sleep, during which there is no significant difference between sexes. ${ }^{9}$ However, in a study which examined only male patients, the ventilatory response decreases more during NREM sleep in comparison with the awakened state. In another study, which examined female patients only, the level of ventilatory response during NREM sleep was similar to that of being awake. ${ }^{10}$

As such, it is widely known that, in the case of normal adults, the ventilatory response to hypoxemia is weakened during sleep, and is closely related to several clinical sequelae of Obstructive Sleep Apnea (OSA). However, the relationship between oxygen saturation and the severity of sleep apnea during REM and NREM sleep has not yet been clarified. Hence, this study investigated how oxygen saturation differs during REM and NREM sleep, in accordance with the severity of sleep apnea, as well as related main factors such as age, body mass index, and hypertension.

\section{METHODS}

\section{Subjects}

We recruited 396 untreated male patients with simple snoring or obstructive sleep apnea syndrome (OSAS), who had undergone nocturnal polysomnography. Mean \pm SD age was $40.8 \pm 12.0$ years and average body mass index (BMI) was $26.7 \pm 3.5 \mathrm{~kg} / \mathrm{m}^{2}$. Subjects were categorized into four groups, simple snoring $(\mathrm{n}=37)$, mild OSAS $(\mathrm{n}=92)$, moderate OSAS $(n=103)$, and severe OSAS $(n=164)$.

Mild OSAS was defined as apnea-hypopnea index (AHI) greater than or equal to 5 but less than 15, moderate OSAS was defined as AHI greater than 15 and less than or equal to 30, and severe OSAS as AHI greater than 30. All subjects met the following inclusion criteria: 1) male, 2) REM sleep time greater than thirty minutes, total sleep time greater than one hundred and eighty minutes, 3) normal electrocardiogram at wakefulness, 4) apnea-hypopnea index (AHI) greater than 5 in OSAS subjects, and 5) no medication except antihypertensive medication.

Exclusion criteria included previous or current cardiovascular disease, pulmonary disorder, diabetes mellitus, substance abuse, history of taking alcohol or other drugs up to 7 days before polysomnographic study, previous diagnosis of sleep disorder except for simple snoring or OSAS, disorders of the autonomic nervous system or endocrine system that can change blood pressure, and a history of surgery or continuous positive airway pressure (CPAP) treatment for OSAS. Informed consent was obtained prior to the study. The protocol was approved by the institutional review board.

\section{Methods}

\section{Nocturnal polysomnography}

Polysomnographic recordings were performed with the Embla N7000 system (Medcare-Embla, Reykjavik, Iceland) using Somnologica version 3.3.1 software (Medcare-Embla, Reykjavik, Iceland) during the time when the subjects were in bed from light-off to light-on. Electroencephalography was monitored using two pairs of $\mathrm{C} 3 / \mathrm{A} 2$ and $\mathrm{C} 4 / \mathrm{A} 1$ leads and O1/ $\mathrm{A} 2$ and O2/A1 leads. Two pairs of electro-oculographic leads were also used. Electromyographic leads were placed on the submentalis and tibialis anterior muscles. Airflow was continuously measured by a thermistor and a nasal pressure cannula. Respiratory movements were monitored using respiratory inductive plethysmographic belts around the chest and abdomen. Oxygen saturation was measured using a pulse oximeter that was put on the left second finger. Average oxygen saturation (\%), lowest oxygen saturation (\%), time of oxygen saturation $<90 \%$ ( $\mathrm{min}$ ), time of oxygen saturation $<80 \%$ ( $\mathrm{min}$ ), and time of oxygen saturation $<70 \%$ ( $\mathrm{min}$ ) were measured. Many variables related to sleep structure, such as time in bed (TIB), total sleep time (TST), sleep period time (SPT), sleep latency (SL), sleep efficiency (SE), stage 1 sleep (S1), stage 2 sleep (S2), slow wave sleep (SWS), REM sleep, wake, slow wave sleep fraction and arousal index, were calculated. The oxygen desaturation event index (ODI) was defined as the number of events per hour in which oxygen saturation decreased by $4 \%$ or more. Hypopnea was defined as a reduction of airflow by $50-80 \%$ for at least 10 sec associated with either oxygen desaturation of at least $4 \%$ or arousal. Apnea was defined as an air flow reduction of $90 \%$ or more for at least $10 \mathrm{sec}$. AHI was calculated by dividing the total number of apneas and hypopneas by the number of hours of sleep. The evaluation of sleep stages and events was based on the American Academy of Sleep Medicine (AASM) manual. ${ }^{11}$

\section{Statistical analysis}

This study utilized SPSS (SPSS Windows, 17.0, SPSS Inc., Chicago, IL, USA) to analyze data. In order to investigate whether the average oxygen saturation differed in accordance with the severity of sleep apnea, the subjects were categorized 
into four groups: simple snoring, and mild, moderate, and severe obstructive sleep apnea. The independent samples t-test was conducted for each group. We analyzed the correlations between the difference of average oxygen saturation during NREM and REM sleep, and demographic variables, AHI, antihypertensive medication therapy, and other variables related to sleep and oxygen saturation. Statistical significance was set as $\mathrm{p}<0.05$. In addition, subjects with severe sleep apnea were categorized into two groups: a group showing higher average oxygen saturation during REM than during NREM sleep, and another group showing higher average oxygen saturation during NREM sleep, for which the independent samples t-test was conducted.

\section{RESULTS}

\section{Demographic and sleep parameter data}

The subjects were categorized into simple snoring $(n=37$,
$35.7 \pm 13.6$ years), mild OSAS ( $n=92,37.8 \pm 12.2$ years), moderate OSAS ( $\mathrm{n}=103,41.4 \pm 11.5$ years), and severe OSAS $(\mathrm{n}=164$, $43.0 \pm 11.3$ years). When the groups were compared in terms of demographic variables and sleep related indicators based upon polysomnography results, there were significant differences in age, BMI, whether taking antihypertensive medication, oxygen saturation, and arousal index $(\mathrm{p}<0.001)$. There were no differences in other demographic variables and the sleep related indicators based on polysomnography (Table 1).

\section{Average oxygen saturation in REM and NREM sleep}

By group, the average oxygen saturation of the simple snoring group was statistically significantly higher during REM than NREM sleep (REM vs. NREM; $96.91 \pm 0.20$ vs. $95.55 \pm 0.22$; $\mathrm{p}<0.001$ ). Patients with mild and moderate sleep apnea showed no significant difference in oxygen saturation between REM and NREM sleep. The oxygen saturation of patients with severe sleep apnea was higher during NREM than REM sleep

Table 1. Demographic data and the data of sleep variables in each group of sleep disordered breathing subjects

\begin{tabular}{|c|c|c|c|c|c|}
\hline Variables & Simple snoring $(N=37)$ & Mild OSAS (N=92) & Moderate OSAS $(\mathrm{N}=103)$ & Severe OSAS $(\mathrm{N}=164)$ & p-value \\
\hline Age & $35.7 \pm 13.6$ & $37.8 \pm 12.2$ & $41.4 \pm 11.5$ & $43.0 \pm 11.3$ & $<0.001$ \\
\hline BMI $\left(\mathrm{kg} / \mathrm{m}^{2}\right)$ & $24.0 \pm 2.6$ & $25.4 \pm 3.3$ & $26.0 \pm 3.3$ & $28.3 \pm 3.3$ & $<0.001$ \\
\hline Anti-HT (\%) & 5.4 & 3.3 & 10.0 & 23.0 & $<0.001$ \\
\hline BDI & $4.9 \pm 5.1$ & $6.6 \pm 6.1$ & $5.5 \pm 5.2$ & $5.9 \pm 4.7$ & 0.339 \\
\hline ESS & $7.6 \pm 5.0$ & $8.7 \pm 4.8$ & $9.5 \pm 4.9$ & $9.8 \pm 4.3$ & 0.042 \\
\hline TST (min) & $387.2 \pm 72.1$ & $364.2 \pm 60.7$ & $373.8 \pm 54.3$ & $378.4 \pm 55.2$ & 0.145 \\
\hline SE (\%) & $89.3 \pm 9.0$ & $87.1 \pm 12.7$ & $90.2 \pm 9.1$ & $89.5 \pm 9.6$ & 0.166 \\
\hline REM sleep (min) & $80.8 \pm 33.5$ & $74.3 \pm 29.3$ & $74.1 \pm 24.9$ & $70.0 \pm 26.1$ & 0.138 \\
\hline REM/TST (\%) & $15.17 \pm 9.05$ & $13.06 \pm 9.6$ & 12.30 .98 & $12.96 \pm 9.35$ & 0.452 \\
\hline SWS (min) & $60.9 \pm 26.9$ & $52.7 \pm 28.1$ & $45.6 \pm 28.2$ & $35.7 \pm 32.5$ & $<0.001$ \\
\hline AHI & $1.6 \pm 1.4$ & $9.7 \pm 2.6$ & $21.6 \pm 4.3$ & $54.4 \pm 16.5$ & $<0.001$ \\
\hline $\mathrm{SpO}_{2}(\%)$ & $96.6 \pm 1.3$ & $95.9 \pm 1.3$ & $95.4 \pm 1.3$ & $92.9 \pm 3.0$ & $<0.001$ \\
\hline Arousal index & $9.4 \pm 9.8$ & $13.5 \pm 9.9$ & $17.5 \pm 7.1$ & $39.2 \pm 20.9$ & $<0.001$ \\
\hline Supine time (min) & $267.2 \pm 125.3$ & $266.9 \pm 92.6$ & $268.9 \pm 95.5$ & $286.1 \pm 89.5$ & 0.311 \\
\hline Non-supine time (min) & $117.5 \pm 93.3$ & $94.6 \pm 80.1$ & $102.1 \pm 86.2$ & $88.3 \pm 80.6$ & 0.214 \\
\hline Supine index (\%) & $67.1 \pm 25.4$ & $73.2 \pm 21.5$ & $71.5 \pm 23.0$ & $75.5 \pm 21.2$ & 0.157 \\
\hline
\end{tabular}

Supine index: [Supine time/(Supine time+Non-supine time)] $\times 100$. OSAS: obstructive sleep apnea syndrome, BMI: body mass index, AntiHT: antihypertensive medication, BDI: Beck depression inventory, ESS: Epworth sleepiness scale, SWS: slow wave sleep, TST: total sleep time, SE: sleep efficiency, REM: rapid eye movement, $\mathrm{SpO}_{2}$ : peripheral capillary oxygen saturation

Table 2. Average oxygen saturation during REM and NREM sleep according to severity of sleep disordered breathing subjects

\begin{tabular}{lccc}
\hline \multicolumn{1}{c}{ Group } & REM Sleep (\%) & NREM Sleep (\%) & p-values \\
\hline Simple snoring (N=37) & $96.91 \pm 1.20$ & $95.54 \pm 1.34$ & $<0.001$ \\
Mild OSAS (N=92) & $96.00 \pm 1.36$ & $95.90 \pm 1.33$ & 0.224 \\
Moderate OSAS (N=103) & $95.46 \pm 1.65$ & $95.39 \pm 1.28$ & 0.490 \\
Severe OSAS (N=164) & $91.79 \pm 4.77$ & $93.15 \pm 2.81$ & $<0.001$ \\
Total (N=396) & $94.16 \pm 3.89$ & $94.67 \pm 2.47$ & $<0.001$ \\
\hline
\end{tabular}

REM: rapid eye movement, N-REM: non-rapid eye movement, OSAS: obstructive sleep apnea syndrome 
(REM vs. NREM; 91.79 \pm 0.37 vs. 93.15 $\pm 0.22 ; \mathrm{p}<0.001$ ) (Table 2 ).

\section{Correlation between oxygen saturation difference during NREM-REM and other variables in patients with severe sleep apnea}

In patients with severe sleep apnea, in order to find potential correlates with the difference in average oxygen saturation between NREM and REM sleep, correlation with age, body mass index, sleep apnea-hypopnea index (AHI), mean oxygen saturation, and lowest oxygen saturation was analyzed. Consequently, there was significant positive correlation with BMI $(\mathrm{r}=0.312 ; \mathrm{p}<0.001)$, AHI $(\mathrm{r}=0.322 ; \mathrm{p}<0.001)$, mean oxygen saturation $(\mathrm{r}=0.452 ; \mathrm{p}<0.001)$, and number of awakenings $(r=0.349 ; p<0.001)$. It showed significant negative correlation with the lowest oxygen saturation $(\mathrm{r}=-0.668 ; \mathrm{p}<0.001)$ and mean oxygen saturation $(\mathrm{r}=-0.552 ; \mathrm{p}<0.001)$.

In particular, severe sleep apnea was strongly associated with BMI, so when it was controlled for, partial correlation analysis showed that the difference between the average oxygen saturations of NREM and REM sleep appeared to have a positive correlation with the degree of arousal $\left(r_{p}=0.286\right.$, $\mathrm{p}<0.001)$, supine index $\left(\mathrm{r}_{\mathrm{p}}=0.200 ; \mathrm{p}<0.05\right)$ and AHI $\left(\mathrm{r}_{\mathrm{p}}=0.229\right.$; $\mathrm{p}<0.001$ ) (Table 3). In patients with severe sleep apnea, when BMI was controlled for, there was a significant correlation between the difference in oxygen saturation between NREM and REM sleep, and the AHI indices (Figure 1).

\section{Comparison based on differences in oxygen saturation of patients with severe obstructive sleep apnea}

We categorized 164 patients with severe obstructive sleep apnea into two groups, and then compared the groups. In Group A ( $\mathrm{n}=108,44.39 \pm 10.84$ years), the average oxygen saturation, which was lower during REM than NREM sleep, was compared with Group B ( $\mathrm{n}=56,39.96 \pm 11.65$ years) average oxygen saturation, which was lower during NREM than REM sleep. As a result, age ( $44.39 \pm 10.84$ vs. $39.96 \pm 11.65, \mathrm{p}=0.018)$ and AHI (57.34 \pm 16.99 vs. $49.97 \pm 15.29, \mathrm{p}=0.004)$ were significantly higher in Group A. Group A's average oxygen saturation $(92.21 \pm 3.38$ vs. $93.98 \pm 1.81, \mathrm{p}<0.001)$ and lowest oxygen saturation $(72.76 \pm 8.34$ vs. $79.63 \pm 5.47, \mathrm{p}<0.001)$ were significantly lower. In terms of the duration of oxygen saturation less than or equal to $90 \%$ ( $81.20 \pm 77.20$ vs. $41.88 \pm 40.85, \mathrm{p}<0.001)$, and oxygen saturation was less than or equal to $80 \%(16.52 \pm 36.44$ vs. 3.11 $\pm 9.51, \mathrm{p}=0.001)$, it was significantly longer in Group A (Table 4). In Group A, after controlling for BMI, there was an interdependence between AHI indices and differences in oxygen saturation during NREM and REM sleep $\left(r_{p}=0.336\right.$, $\mathrm{p}<0.001)$. In Group B, there was no interdependence $\left(r_{p}=-0.241\right.$, $\mathrm{p}=0.074$ ) (Figure 2).

\section{DISCUSSION}

In this study, it was confirmed that selective difference in average oxygen saturation during NREM and REM sleep occurred according to the severity of sleep breathing disorder (SBD). In the case of simple snoring, the average oxygen saturation during REM was statistically significantly higher. Patients with mild and moderate OSAS showed no significant difference in oxygen saturation during REM and NREM sleep. In the case of patients with severe OSAS, the average oxygen saturation was lower during REM than NREM sleep. Previous studies reported that apnea or hypopnea can be further exacerbated during REM sleep, as compared to NREM sleep ${ }^{12,13}$ and that average oxygen saturation was lower during REM sleep, as compared to NREM sleep. ${ }^{14}$ However, because these previous studies were conducted on patients with REM-dependent obstructive sleep apnea with relatively lower AHI and

Table 3. The difference of NREM-REM average oxygen saturation correlation with AHI, supine position time, and oxygen variables adjusted by BMI in severe obstructive sleep apnea syndrome group

\begin{tabular}{|c|c|c|c|c|c|c|c|c|}
\hline $\begin{array}{c}\text { Main } \\
\text { variables }\end{array}$ & $\begin{array}{c}\text { Difference } \\
\text { of average } \mathrm{SpO}_{2}\end{array}$ & Age & AHI & $\begin{array}{c}\text { Average } \\
\mathrm{SpO}_{2} \\
\end{array}$ & $\begin{array}{c}\text { Lowest } \\
\mathrm{SpO}_{2}\end{array}$ & $\begin{array}{c}\text { Average } \\
\text { desaturation }\end{array}$ & $\begin{array}{c}\text { Supine } \\
\text { index }\end{array}$ & $\begin{array}{c}\text { Arousal } \\
\text { index }\end{array}$ \\
\hline Age & 0.087 & & & & & & & \\
\hline AHI & $0.229^{*}$ & -0.002 & & & & & & \\
\hline Average $\mathrm{SpO}_{2}$ & $-0.490^{\dagger}$ & -0.130 & $-0.462^{\dagger}$ & & & & & \\
\hline Lowest $\mathrm{SpO}_{2}$ & $-0.628^{\dagger}$ & -0.093 & $-0.434^{\dagger}$ & $0.753^{\dagger}$ & & & & \\
\hline Average desaturation & $0.387^{\dagger}$ & 0.096 & $-0.393^{\dagger}$ & $-0.749^{\dagger}$ & $-0.790^{\dagger}$ & & & \\
\hline Supine index & $0.200^{*}$ & 0.011 & $-0.433^{\dagger}$ & $-0.234^{*}$ & $-0.183^{*}$ & 0.131 & & \\
\hline Arousal index & $0.286^{\dagger}$ & -0.108 & $-0.542^{\dagger}$ & $-0.384^{\dagger}$ & $-0.357^{\dagger}$ & $0.438^{\dagger}$ & $0.223^{*}$ & \\
\hline Anti-HT (\%) & -0.015 & $0.370^{\dagger}$ & -0.027 & -0.105 & 0.001 & 0.001 & -0.063 & -0.072 \\
\hline
\end{tabular}

Difference of average $\mathrm{SpO}_{2}$ : the difference between NREM-REM average oxygen saturation, Supine index: [Supine time/(Supine time+Nonsupine time)] $\times 100$. $r=$ partial correlation coefficient adjusted by BMI. ${ }^{*} \mathrm{p}<0.05,{ }^{\dagger} \mathrm{p}<0.001$. N-REM: non-rapid eye movement, REM: rapid eye movement, AHI: apnea-hypopnea index, BMI: Body Mass Index, HTN: hypertension, Anti-HT: antihypertensive medication 
milder severity of apnea than patients with non-REM-dependent obstructive sleep apnea, the results are expected to be inconsistent with the finding in this study, which examined patients with various severities of SBD. ${ }^{15,16}$

To our knowledge, there have not been any studies that investigated the reason why average oxygen saturation differs during REM and NREM sleep in accordance with SBD. We hypothesized that the distribution of events of sleep apnea may

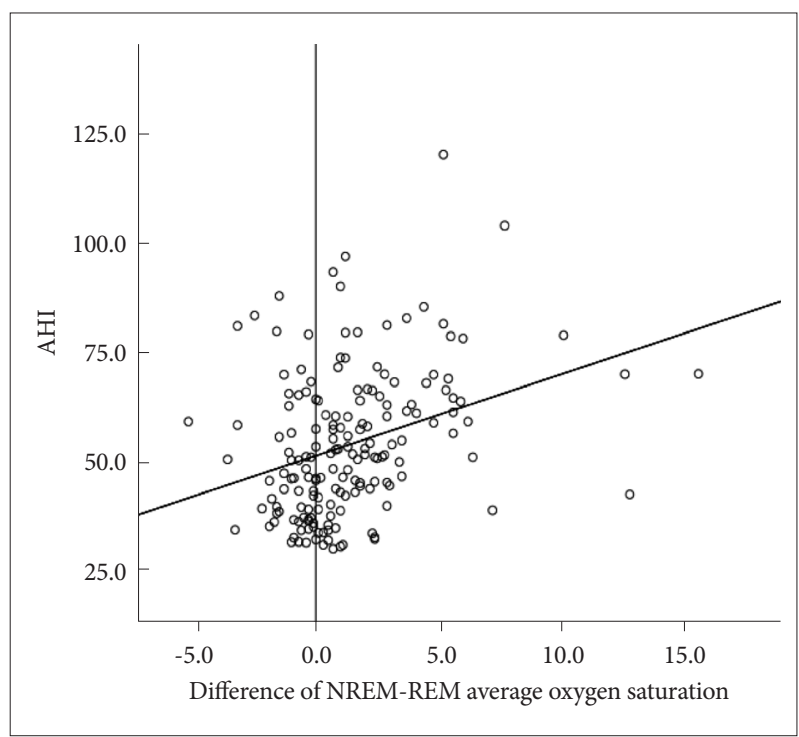

Figure 1. The correlation between apnea-hypopnea index and the difference in the average oxygen saturations during rapid eye movement and non-rapid eye movement sleep, when controlled for body mass index, in the severe obstructive sleep apnea group $\left(r_{p}=0.229, p<0.05\right)$. N-REM: non-rapid eye movement, REM: rapid eye movement. differ in accordance with the severity of SBD. In the case of simple snoring, sleep apnea or snoring are more likely to happen during NREM than REM sleep. In cases of mild and moderate obstructive sleep apnea, they happen regardless of REM and NREM sleep, and in cases of severe obstructive sleep apnea, sleep apnea happens more intensely during REM than NREM sleep.

It has been reported that there is no correlation between the severity of obstructive sleep apnea and sleep stage, ${ }^{17}$ but there have been reported results where AHI-NREM was far higher than AHI-REM in the cases of patients with severe obstructive sleep apnea. ${ }^{12,15,18}$ However, some have argued that AHI during REM sleep can be relatively undervalued, considering the fact that the ratio of REM sleep to total sleeping time is decreased when sleep apnea is more severe. ${ }^{19}$ In this regard, further comparative study is required, measuring AHIs in REM and NREM sleep and compensating for total sleeping time.

As a result of the analysis of the correlation between the difference in average oxygen saturation between NREM and REM sleep, and age, supine figure, the non-supine Index, and variables related to oxygen, it was found that there was no statistically significant correlation between the difference in oxygen saturation, and age or hypertension. However, AHI did demonstrate a significant correlation with the difference in average oxygen saturation. The fact that in cases of severe obstructive sleep apnea, the difference in average oxygen saturation between NREM and REM sleep correlated with AHI, may partially explain why Continuous Positive Airway Pressure (CPAP) is increased, which is due to the high possibility of severe hypoxia during REM sleep. ${ }^{20}$

Table 4. Comparison of subgroups according to average oxygen saturation in the severe obstructive sleep apnea syndrome group

\begin{tabular}{|c|c|c|c|}
\hline Main variables & A group $(\mathrm{N}=108)$ & B group $(\mathrm{N}=56)$ & p-values \\
\hline Age (years) & $44.39 \pm 10.84$ & $39.96 \pm 11.65$ & 0.018 \\
\hline $\mathrm{BMI}\left(\mathrm{kg} / \mathrm{m}^{2}\right)$ & $28.72 \pm 3.31$ & $27.53 \pm 3.13$ & 0.062 \\
\hline TST (min) & $376.37 \pm 56.47$ & $381.49 \pm 56.19$ & 0.550 \\
\hline Systolic BP & $132.80 \pm 8.22$ & $132.33 \pm 8.79$ & 0.738 \\
\hline Diastolic BP & $87.51 \pm 10.61$ & $86.79 \pm 10.07$ & 0.682 \\
\hline AHI & $57.34 \pm 16.99$ & $49.97 \pm 15.29$ & 0.004 \\
\hline Average $\mathrm{SpO}_{2}$ & $92.21 \pm 3.38$ & $93.98 \pm 1.81$ & $<0.001$ \\
\hline Lowest $\mathrm{SpO}_{2}$ & $72.76 \pm 8.34$ & $79.63 \pm 5.47$ & $<0.001$ \\
\hline $\mathrm{SpO}_{2}<90 \%(\min )$ & $81.20 \pm 77.20$ & $41.88 \pm 40.85$ & $<0.001$ \\
\hline $\mathrm{SpO}_{2}<80 \%(\mathrm{~min})$ & $16.52 \pm 36.44$ & $3.11 \pm 9.51$ & 0.001 \\
\hline $\mathrm{SpO}_{2}<70 \%(\mathrm{~min})$ & $2.66 \pm 11.33$ & $0.007 \pm 0.04$ & 0.016 \\
\hline Arousal index & $40.96 \pm 22.45$ & $35.63 \pm 17.80$ & 0.102 \\
\hline Difference of average $\mathrm{SpO}_{2}$ & $2.74 \pm 2.69$ & $-1.16 \pm 1.03$ & $<0.001$ \\
\hline
\end{tabular}

Mean \pm standard deviation. Difference of average $\mathrm{SpO}_{2}$ : the difference of NREM-REM average oxygen saturation. A group: average saturation (\%) of NREM >average saturation (\%) of REM, B group: average saturation (\%) of REM >average saturation (\%) of NREM. BMI: Body Mass Index, TST: total sleep time, BP: blood pressure, AHI: apnea-hypopnea index 


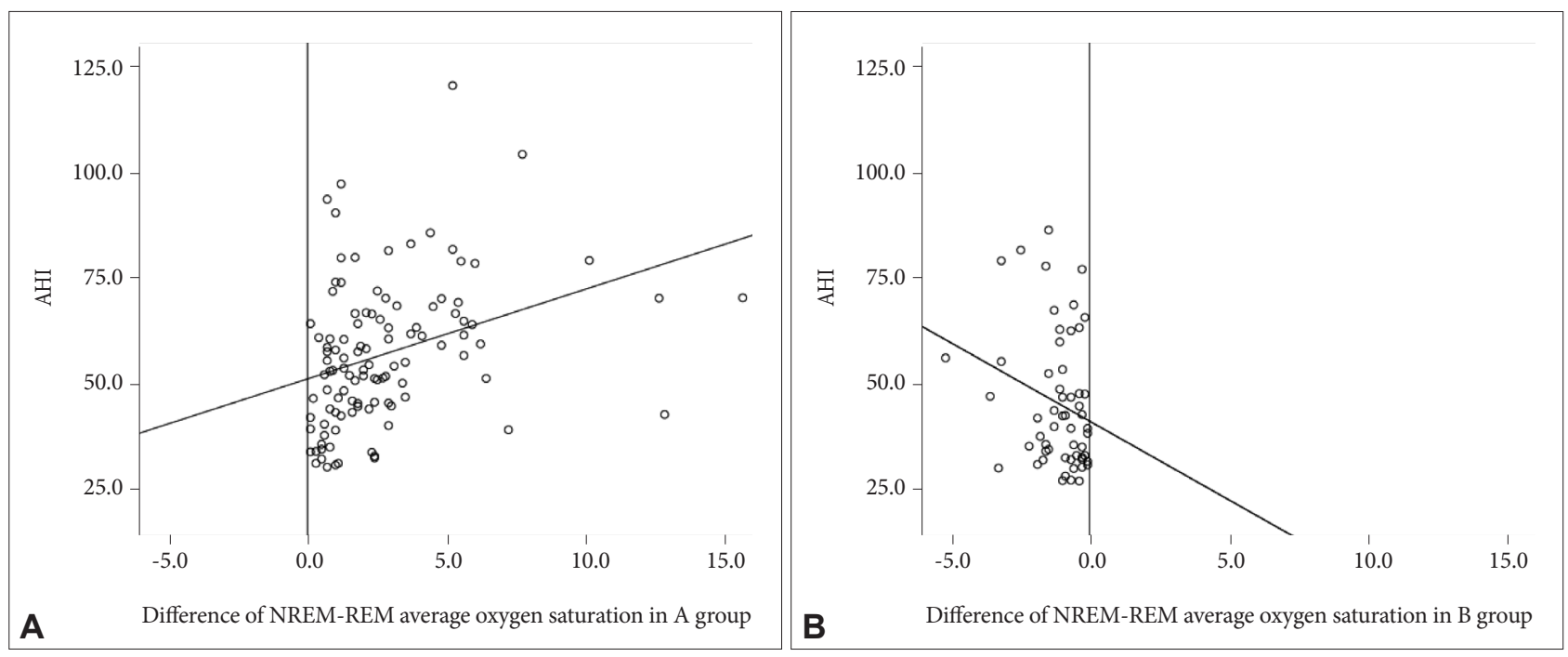

Figure 2. A: The correlation between apnea-hypopnea index and the difference of non-rapid eye movement-rapid eye movement average oxygen saturation controlling for age and body mass index is shown by a positive correlation $\left(r_{p}=0.336, p<0.001\right)$ in patients with severe obstructive sleep apnea syndrome in group A. B: The correlation between apnea-hypopnea index and the difference of non-rapid eye movement-rapid eye movement average oxygen saturation controlling for age and body mass index is not shown by a significant correlation $\left(r_{p}=\right.$ $-0.241, p=0.074)$ in patients with severe obstructive sleep apnea syndrome in group B. A group: average saturation (\%) of NREM >average saturation (\%) of REM, B group: average saturation (\%) of REM >average saturation (\%) of REM. REM: rapid eye movement.

It is known that patients with positional obstructive sleep apnea with sleeping time longer than or equal to 15 minutes and $\mathrm{AHI}$ higher than or equal to 5 , supine $\mathrm{AHI}$ is at least twice non-supine AHI and have lower rates of obesity than patients with non-positional obstructive sleep apnea. They are also known to have mild and moderate symptoms of obstructive sleep apnea. ${ }^{21}$ Previous research showed that non-supine position has no clear correlation with severity of obstructive sleep apnea. ${ }^{22}$ However, this study showed that in the case of patients with severe sleep apnea, AHI and supine index showed correlation $\left(\mathrm{r}_{\mathrm{p}}=0.433, \mathrm{p}<0.001\right)$.

When the patients with severe OSA are compared, having been categorized into a group with low average oxygen saturation during REM sleep and another group with low average oxygen saturation during NREM sleep, the group with low oxygen saturation during REM sleep showed higher AHI, age, and BMI than its counterparts. Its average oxygen saturation and lowest oxygen saturation was lower, and the duration of oxygen saturation less than or equal to $90 \%$ or $80 \%$ was relatively longer. Like previous research, in this study, the apnea period was estimated to be longer during REM than NREM sleep. ${ }^{23,24}$ This is because the degree of arousal is lower during REM than NREM sleep. ${ }^{25}$ Accordingly, it could be deduced that the hypoxic period can lengthen when the sleep apnea index is higher, which makes sleep apnea more severe during REM sleep. In this regard, the cases of patients whose oxygen saturation is obviously lower during REM sleep required more proactive treatment.

This study has a limitation that the AHI of REM and NREM sleep were not separately analyzed. In night polysomnography, normally sleep apnea is evenly observed throughout REM and NREM sleep. However, in the case of certain patients, apnea occurs more during REM sleep. In particular, when sleep apnea happens more during REM sleep, AHI during REM sleep is typically at least twice that during NREM sleep, and is referred to as REM Sleep-Dependent Obstructive Sleep Apnea, which was not analyzed in this study. However, it is known that patients with REM Sleep-Dependent Obstructive Sleep Apnea tend to be relatively young female patients with mild OSA. ${ }^{26,27}$ In order to resolve this limitation, this study examined only male subjects, but for more precise evaluation, in further studies that separate REM and NREM sleep, the AHI for each phase needs to be analyzed.

This study, for the first time, suggests that oxygen saturation of REM and NREM sleep can differ in accordance with the severity of sleep disordered breathing. This study also suggests that, in the case of patients whose hypoxia becomes severe during REM sleep, continuous positive airway pressure (CPAP) needs to be more actively controlled to resolve hypoxia, as well as oxygen saturation during NREM and REM sleep.

\section{Acknowledgments}

This paper was supported financially by Konkuk University (Seoul, Korea) in 2015. The financial sponsors played no role in the design, execution, analysis and interpretation of data or writing of the study.

\section{REFERENCES}

1. Kryger MH, Roth T, Dement WC. Principles and Practice of Sleep Medicine. Philadelphia, PA: Saunders/Elsevier; 2011. 
2. Sowho M, Amatoury J, Kirkness JP, Patil SP. Sleep and respiratory physiology in adults. Clin Chest Med 2014;35:469-481.

3. Muller NL, Francis PW, Gurwitz D, Levison H, Bryan AC. Mechanism of hemoglobin desaturation during rapid-eye-movement sleep in normal subjects and in patients with cystic fibrosis. Am Rev Respir Dis 1980; 121:463-469.

4. Aserinsky E. Periodic respiratory pattern occurring in conjunction with eye movements during sleep. Science 1965;150:763-766.

5. Tabachnik E, Muller NL, Bryan AC, Levison H. Changes in ventilation and chest wall mechanics during sleep in normal adolescents. J Appl Physiol Respir Environ Exerc Physiol 1981;51:557-564.

6. Ramirez JM, Garcia AJ 3rd, Anderson TM, Koschnitzky JE, Peng YJ, Kumar GK, et al. Central and peripheral factors contributing to obstructive sleep apneas. Respir Physiol Neurobiol 2013;189:344-353.

7. Mignot E. Excessive daytime sleepiness: population and etiology versus nosology. Sleep Med Rev 2008;12:87-94.

8. Douglas NJ, White DP, Weil JV, Pickett CK, Martin RJ, Hudgel DW, et al. Hypoxic ventilatory response decreases during sleep in normal men. Am Rev Respir Dis 1982;125:286-289.

9. Tarbichi AG, Rowley JA, Shkoukani MA, Mahadevan K, Badr MS. Lack of gender difference in ventilatory chemoresponsiveness and post-hypoxic ventilatory decline. Respir Physiol Neurobiol 2003;137:41-50.

10. White DP, Douglas NJ, Pickett CK, Weil JV, Zwillich CW. Hypoxic ventilatory response during sleep in normal premenopausal women. Am Rev Respir Dis 1982;126:530-533.

11. Kushida CA, Littner MR, Morgenthaler T, Alessi CA, Bailey D, Coleman J Jr, et al. Practice parameters for the indications for polysomnography and related procedures: an update for 2005. Sleep 2005;28:499521.

12. Muraki M, Kitaguchi S, Ichihashi $H$, Haraguchi R, Iwanaga T, Kubo H, et al. Apnoea-hypopnoea index during rapid eye movement and nonrapid eye movement sleep in obstructive sleep apnoea. J Int Med Res 2008;36:906-913.

13. Farney RJ, Walker LE, Jensen RL, Walker JM. Ear oximetry to detect apnea and differentiate rapid eye movement (REM) and non-REM (NREM) sleep. Screening for the sleep apnea syndrome. Chest 1986; 89:533-539.

14. Findley LJ, Wilhoit SC, Suratt PM. Apnea duration and hypoxemia during REM sleep in patients with obstructive sleep apnea. Chest 1985; 87:432-436.
15. Haba-Rubio J, Janssens JP, Rochat T, Sforza E. Rapid eye movement-related disordered breathing: clinical and polysomnographic features. Chest 2005;128:3350-3357.

16. Lee YJ, Lee SJ, Kang DJ. Clinical and polysomnographic characteristics of REM sleep-dependent obstructive sleep apnea. Sleep Med Psychophysiol 2008;15:77-81.

17. Boudewyns A, Punjabi N, Van de Heyning PH, De Backer WA, O'Donnell CP, Schneider H, et al. Abbreviated method for assessing upper airway function in obstructive sleep apnea. Chest 2000;118:10311041.

18. Oksenberg A, Arons E, Nasser K, Vander T, Radwan H. REM-related obstructive sleep apnea: the effect of body position. J Clin Sleep Med 2010;6:343-348.

19. Eiseman NA, Westover MB, Ellenbogen JM, Bianchi MT. The impact of body posture and sleep stages on sleep apnea severity in adults. J Clin Sleep Med 2012;8:655-666A.

20. Oksenberg A, Silverberg DS, Arons E, Radwan H. The sleep supine position has a major effect on optimal nasal continuous positive airway pressure: relationship with rapid eye movements and non-rapid eye movements sleep, body mass index, respiratory disturbance index, and age. Chest 1999;116:1000-1006.

21. Kang HH, Kang JY, Lee SH, Moon HS. The clinical characteristics between the positional obstructive sleep apnea patients with the non-positional obstructive sleep apnea patients. Sleep Med Psychophysiol 2012; 19:22-26.

22. Menon A, Kumar M. Influence of body position on severity of obstructive sleep apnea: a systematic review. ISRN Otolaryngol 2013;2013: 670381

23. George CF, Millar TW, Kryger MH. Sleep apnea and body position during sleep. Sleep 1988;11:90-99.

24. Jennum P, Borgesen SE. Intracranial pressure and obstructive sleep apnea. Chest 1989;95:279-283.

25. Berry RB, Gleeson K. Respiratory arousal from sleep: mechanisms and significance. Sleep 1997;20:654-675.

26. Koo BB, Dostal J, Ioachimescu O, Budur K. The effects of gender and age on REM-related sleep-disordered breathing. Sleep Breath 2008; 12:259-264.

27. Koo BB, Patel SR, Strohl K, Hoffstein V. Rapid eye movement-related sleep-disordered breathing: influence of age and gender. Chest 2008; 134:1156-1161. 